\title{
Ecotoxicological effects of silver nanoparticles in marine mussels
}

\section{Calisi A. ${ }^{1,2^{\circ}}$; Lorusso C ${ }^{1}$, Gallego-Urrea J.A. ${ }^{3}$; Hassellöv M. ${ }^{3}$; Dondero F. ${ }^{1 *}$}

${ }^{1}$ Department of Science and Technological Innovation, Università degli Studi del Piemonte

Orientale-Vercelli, Novara, Alessandria. Viale Michel 11, 15121 Alessandria, Italy.

${ }^{2}$ Department of Engineering for Innovation, University of Salento, via Prov.le per Monteroni,

73100, Lecce, Italy

${ }^{3}$ Department of Marine Sciences, University of Gothenburg, Kristineberg marine research station, Kristineberg 566, 45178 Fiskebäckskil, Sweden

${ }^{\circ}$ Present address: Department of Engineering for Innovation, University of Salento, via Prov.le per Monteroni, 73100, Lecce, Italy

*Corresponding author: Dondero F. Department of Science and Technological Innovation, Università degli Studi del Piemonte Orientale-Vercelli, Novara, Alessandria. Viale Michel 11, 15121 Alessandria, Italy. Tel +390131360415; email: francesco.dondero@uniupo.it

Keywords: bivalves; hazard assessment; logit; regression analysis; toxicity,

Author's full details:

- Antonio Calisi, PhD. Department of Engineering for Innovation, University of Salento, via Prov.le per Monteroni, 73100, Lecce, Italy, email: antonio.calisi@unisalento.it

- Candida Lorusso, Department of Science and Technological Innovation, Università degli Studi del Piemonte Orientale-Vercelli, Novara, Alessandria. Viale Michel 11, 15121 Alessandria, Italy.; email: candida.lorusso@ uniupo.it

- Julián Alberto Gallego Urrea, PhD. Department of Marine Sciences, University of Gothenburg, Kristineberg marine research station, Kristineberg 566, 45178 Fiskebäckskil, Sweden. Tel. +46 765506372; email: julian.gallego@ marine.gu.se

- Martin Hassellöv, Professor. Department of Marine Sciences, University of Gothenburg, Kristineberg marine research station, Kristineberg 566, 45178 Fiskebäckskil, Sweden. Tel. +46 765506372; email: martin.hassellov@ marine.gu.se

- Francesco Dondero, PhD. Department of Science and Technological Innovation, Università degli Studi del Piemonte OrientaleVercelli, Novara, Alessandria. Viale Michel 11, 15121 Alessandria, Italy. Tel +390131360415; email:

francesco.dondero@uniupo.it 


\section{Abstract}

2 In the marine bioindicator species M. galloprovincialis Lam we predicted toxicity and

3 bioaccumulation of $5 \mathrm{~nm}$ alkane-coated and $50 \mathrm{~nm}$ uncoated silver nanoparticles (AgNPs) along

4 with $\mathrm{Ag}^{+}$, as a function of the actual dose level. We generated a time persistence model of silver

5 concentration in seawater and used the Area Under the Curve (AUC) as independent variable in

6 hazard assessment. This approach allowed us to evaluate unbiased ecotoxicological endpoints for

7 acute (survival) and chronic toxicity (byssal adhesion). Logistic regression analysis rendered

$8 \quad \mathrm{LC}_{50} 0_{96 \mathrm{~h}}$ values of $0.68 \pm 0.08 ; 1.00 \pm 0.20 ; 1.00 \pm 0.42 \mathrm{mg} \mathrm{h} \mathrm{L}^{-1}$ respectively for $\mathrm{Ag}^{+}, 5 \mathrm{~nm}$ and 50

$9 \mathrm{~nm}$ AgNP posing no evidence the silver form is a necessary variable to predict the survival

10 outcome. By contrast, for byssal adhesion regression analysis revealed a much higher toxicological

11 potential of $\mathrm{Ag}^{+}$vs AgNPs, $0.0021 \pm 0.0009 ; 0.053 \pm 0.016 ; 0.021$ (no computable error for $50 \mathrm{~nm}$

$12 \mathrm{AgNP}) \mathrm{mg} \mathrm{h} \mathrm{L}^{-1}$, and undoubtedly confirmed a role of the silver form.

13 Bioaccumulation was higher for $\mathrm{Ag}^{+}>5 \mathrm{~nm} \mathrm{AgNP}>50 \mathrm{~nm}$ AgNP reflecting a parallel with the 14 preferential uptake route / target organ.

15 We, eventually, provided a full range of toxicological endpoints to derive risk quotients.

\section{Introduction}

OECD emphasized four metal or metal oxide engineered nanoparticles with high interest due to

19 their inherent properties. According to the Nanotechnology Product Database

20 (https://product.statnano.com), silver nanoparticles (AgNPs) are, currently, found in 950 consumer

21 products belonging to 15 different industrial sectors, with medicine, textile, cosmetics, home

22 appliance, environment and construction dominating the scene. In addition, in the 2007-2017

23 decade nearly 5000 new applications were registered in different fields, such as consumer, medical,

24 agricultural and industrial (Sim et al., 2018). AgNPs attracted increasing interest due to their unique

25 physical, chemical and biological (antibacterial) properties compared to their macro-scaled

26 counterparts (Chen et al., 2009; Singh et al., 2015). Moreover, as other metal and metal oxides, 
27 AgNP can be obtained through green chemistry, therefore are promising sustainable next generation 28 materials (Beyene et al., 2017; Sharma et al., 2009). AgNPs have peculiar physicochemical properties: high electrical and thermal conductivity, chemical stability, catalytic activity and nonlinear optical behavior (Krutyakov et al., 2008). The physicochemical characteristics of metal-based NPs are fundamental to determine their environmental fate as well as speciation in water. Dissolution, aggregation and sedimentation of AgNP are likewise crucial processes, in particular in the marine environments, able to affect their bioavailability and toxicological properties (Darlington et al., 2009; Markus et al., 2015). From an ecotoxicological point of view, the scientific community is still arguing if the environmental release of engineered nanoparticles may pose an ecological risk greater than that determined by bulk materials (non-nano) and/or the ionic forms. Several reports question for a harsher effect of nanomaterials in different model species (Shaw and Handy, 2011; Schultz et al., 2016; Bourdineaud et al., 2021; Parsal and Kumar 2021), however, exceptions were reported that need consideration (an example is given in Lahive et., 2017). With regards to the marine environment despite the information has linearly increased in the last decade, the big picture of NP toxicity is still limited due to additional technical difficulties. Indeed, the behavior of engineered NPs in the seawater is highly influenced by aggregation, agglomeration sedimentation, mobility, speciation and dissolution (Timerbaev et al., 2021), confounding factors that increase the uncertainty in hazard and risk assessment.

Several studies in the marine matrix focused on primary producers and consumers, such as algae and bivalves i.e. Mytilus congeners. Mussels are -indeed- widely recognized as a NP sensitive species with also an ecological relevance (Baun et al., 2008; Moore, 2006; Canesi et al., 2012). A quick literature survey says that great attention was given to AgNPs with different coatings (polyvinyl pyrrolidone dominated the scene) and sizes (from 5 to $100 \mathrm{~nm}$ are well represented), but paradoxically, the vast majority of the studies on mussels focused on sublethal effects viz. biomarkers. Moreover, most reports were centered on a few selected concentrations (the mode is in 52 the $0.010-0.10 \mathrm{mg} \mathrm{L}^{-1}$ bin). To our knowledge, in fact, if excluding Katsumiti et al. (2015) provding 
cumulative toxicity curves along with LC50 for hemocytes and isolated gills cells exposed to maltose AgNP of different sizes; and Auguste et al. (2018) providing cumulative toxicity curves along with EC50 for hemocytes lysosomal membrane stability (LMS) and larval development, no full range effects for acute and chronic toxicity has been yet determined in adult specimens of the Mytilus congeners. By contrast, a few dozen studies have reported biomarker data.

The aim of this work, therefore, was to fill this gap providing a comprehensive acute (survival) and chronic (byssal adhesion) hazard assessment in M. galloprovincialis Lam. To this aim, $5 \mathrm{~nm}$ alkanecoated and $50 \mathrm{~nm}$ uncoated AgNPs were used in a nominal concentration range comprising 5 magnitude orders $\left(0.001-10.0 \mathrm{mg} \mathrm{L}^{-1}\right)$. To establish the genuine toxicological potential of AgNPs and allow an unbiased comparison with ionic silver $\left(\mathrm{Ag}^{+}\right)$, we first generated a persistence model to calculate the variation of the silver titer as a function of time in seawater and, hence, we used the Area Under the Curve (AUC), i.e. the silver integrated dose, as the principal driver of toxicity and bioaccumulation in (multiple) regression analysis.

\section{Materials and Methods}

\section{Materials}

Ionic silver in the form of nitrate was obtained from Sigma-Aldrich (99\% purity). 5nm alkanecoated AgNP (particle range 3-8 nm) were obtained from Amepox sp. Z o. O. (Poland) in the form of a stable aqueous $1 \mathrm{~g} \mathrm{~L}^{-1}$ dispersion. According to the manufacturer these particles have an alkanecoating accounting for $18 \%$ weight whose composition represents an industrial secret and therefore its exact composition is unknown. Primary characterization of Amepox AgNP was previously reported (Ribeiro et al., 2014). A summary of primary characterization is presented in Section 3.1 along with secondary characterization.

$50 \mathrm{~nm}$ uncoated AgNP were obtained from NanoTrade s.r.o. (Czech Republic) in the form of a grey / brownish powder. Primary characterization of NanoTrade AgNP was previously reported (Diez- 
Ortiz et al., 2015). Briefly, TEM analysis showed primary particles in the range of 50-80 nm in size, forming larger nano-to micron-sized aggregates.

\section{Nanoparticle secondary characterization and aggregation experiments}

Characterization of the stock solutions were done by dynamic light scattering. For the aggregation experiments the instrument used was a Zetasizer (Malvern Panalytical Ltd, Malvern, UK), with the Zetasizer software version 6.20 .

Different seawater media was used to test for nanoparticle stability: 35\%o Artificial Sea Water (ASW; Instant Ocean, VA, USA), 35\%o natural sea water (NSW) and 35\%o Natural Sea water filtered (NSWf) with very similar results.

Short term experiments were performed to investigate initial aggregation rates of the $5 \mathrm{~nm} \mathrm{AgNPs}$.

The stock solutions were prepared before the experiments and mixed with the media and MQ to the desired concentrations in regular DLS cuvettes, mixed briefly using a vortex mixer and inserted immediately in the instrument. The measurement was started at a fixed attenuator and measurement position with the correlation time set to 2 seconds and 120 data points were generally obtained.

During long term experiments (up to 4 days) the first measurement (day zero) was obtained by creating an average result from the short term data points. The cuvettes were stored at dark and three measurements were performed ( 3 runs of 20 seconds each) in the following days. To evaluate the effect of particles sedimentation, the samples were shaken after performing the measurement and a new measurement was done.

\section{Exposure experimental design}

Adult mussels (Mytilus galloprovincialis Lam.) were sampled from a natural population in front of Gabicce Mare (Italy, North Adriatic Sea) and transported to laboratory in a cool box under controlled condition $\left(0-4^{\circ} \mathrm{C}\right)$. Animals $(n=600)$ were selected to form homogeneous groups in size (5-6 cm), separated from one another by carefully cutting off the byssal threads and washed with 
104 seawater. Then, mussels were acclimatized for at least 4 weeks in static tanks containing filtered

$10535 \%$ aerated artificial sea water ASW (Instant Ocean, VA, USA), $\mathrm{pO}_{2}>8.0 \mathrm{mg} / \mathrm{L}, \mathrm{pH} 8.1 \pm 0.5$.

106 Temperature was kept constant at $16 \pm 1^{\circ} \mathrm{C}$ and animals fed daily during acclimatation with a

107 commercial nutritive solution for marine invertebrates (Marine Liquifry, Interpret, UK).

108 Mussels were randomly assigned to experimental (Ag treated) and reference not-exposed groups.

109 Five different nominal exposure levels -from $10 \mathrm{mg} \mathrm{L}^{-1}$ to $0.001 \mathrm{mg} \mathrm{L}^{-1} \mathrm{Ag}$ with a $\log 10$ series, and

1102 reference control groups were set-up for each replicated experiment $(n=4)$. One control group

111 contained the alkane-coating at $1.8 \mathrm{mg} \mathrm{L}^{-1}$ to resemble the worst-case condition, howeer, control

112 data were merged during the analysis since no significant effects were found due to coating. The

113 nominal concentrations of $50 \mathrm{~nm}$ AgNP were adjusted to obtain similar values of the $5 \mathrm{~nm}$ AgNP

114 that account for the alkane coating (see paragraph Table 1).

115 Exposed mussels were treated for 24 or $96 \mathrm{~h}$ with each silver form, according to the test to be

116 performed. Silver was added daily -along with water renewal- from freshly prepared stock water-

117 suspension/solution or from the $5 \mathrm{~nm}$ stable stock solution. In general, 15 mussels per each

118 condition/ replicate were tested. Animals were not fed during the exposures. After the acclimation,

11915 mussels were randomly placed into new $21 \mathrm{~L}$ polypropylene plastic vessels with $35 \%$ aerated

$120(110 \mathrm{~L} / \mathrm{h}) \mathrm{ASW}, \mathrm{pH} 8.1 \pm 0.5$, at a density of 1 animal/L at $16^{\circ} \mathrm{C}$. The $50 \mathrm{~nm} \mathrm{AgENPs}$ stock

121 solution was prepared according to the "PROSPEcT 2010: Protocol for Nanoparticle Dispersion"

122 (PROSPEcT, 2010)

123 (https://nanotechia.org/sites/default/files/files/PROSPECT_Dispersion_Protocol.pdf). Briefly,

124 nanoparticles were weight and placed in a glass vial; a few drops of MilliQ water were added to

125 create a concentrated nanoparticle paste and then more water was added to make up the desired

126 concentration $\left(0.5-1.0 \mathrm{~g} \mathrm{~L}^{-1}\right)$. After sonication for $30 \mathrm{sec}$ with an ultrasound probe at middle power

127 intensity the suspension was stirred by hand for $10 \mathrm{~s}$. Silver nitrate was prepared in ultrapure water

128 at $0.5 \mathrm{~g} \mathrm{~L}^{-1}$. The silver titer was evaluated ex post in all stock solutions by chemical analysis (see 
129 below). Physical/chemical parameters ( $\mathrm{pH}, \mathrm{T}, \mathrm{O} 2)$ were checked at least daily along with

130 ecotoxicological parameters.

131

132

96-h acute toxicity test - survival

133 Mortality was evaluated daily before the water renewal and at the end of the exposure, $96 \mathrm{~h}$.

134 Mussels were considered dead (and withdrew from the aquaria) when the lack of the adductor

135 muscle activity was recorded. At least 4 independent exposure trials were carried out.

136

137

96-h chronic toxicity test - byssal adhesion.

138 A simple binomial procedure was set up to test byssal performance in immersed mussels after $24 \mathrm{~h}$

139 exposure to Ag. Mussels were considered positive for adhesion if functional byssal threads of a

140 specimen were found attached to the tank or to another individual mussel. At least 4 independent

141 exposures per each condition were carried out.

142

143 Determination of silver concentration in water samples.

$14450 \mathrm{ml}$ seawater samples were withdrawn from the exposure vessels at regular intervals of 1, 4, $24 \mathrm{~h}$.

145 For soluble silver, the water samples were ultracentrifuged at $100,000 \mathrm{~g}$ for $2 \mathrm{~h}$ at $20^{\circ} \mathrm{C}$.

146 Silver amounts at time zero $\left(\mathrm{t}_{0}\right)$ were calculated from the stock solution concentration.

147 Samples were analyzed for silver content by Inductively Coupled Plasma Mass-Spectrometry (ICP-

148 MS) according to the unified referenced procedure UNI EN ISO 17294-2:2016 including certified

149 materials as a reference standard. AgNP samples were acid digested before quantification according

150 to the procedure EPA 3051A. The LOD for silver was $0.0005 \mathrm{mg} \mathrm{L}^{-1}$.

151

152 Determination of silver concentration in mussel tissues.

153 Total silver burdens were evaluated in whole soft tissues and isolated tissues, viz. gills and digestive

154 glands from mussels exposed for 4 days to the different silver forms. Tissue biopsies were washed 
155

156

157

158

159

160

161

162

163

164

165

166

167

168

169

170

171

172

173

174

175

176

177

178

179

180

under cold tap water for 30 seconds, rinsed for 20 seconds in several volumes of cold $1 \mathrm{mM}$ cysteine solution, rinsed twice in seawater, once in ultrapure water, damped and flash frozen in liquid nitrogen. Samples were stored at $-80^{\circ} \mathrm{C}$ until needed. For metal content analysis, the soft tissue from single specimens were thawed and homogenized with the addition of $5 \mathrm{ml}$ of ultrapure water per gram of tissue. Samples were acid digested according to the procedure EPA 3051A using a microwave oven by the addition of 10 volume of a $3: 1$ mixture of concentrated $\mathrm{HCl}: \mathrm{HNO}_{3}$ (aqua regia) and further analyzed by ICP-MS analysis according to the referenced procedure UNI EN ISO 17294-2:2016 including certified materials as a reference standard.

The limit of detection (LOD) was $0.005 \mathrm{mg} \mathrm{kg}^{-1}$

\section{Regression analysis and statistics.}

For the persistence model, non-linear regression of silver data in the water column was performed in MS-Excl (Microsoft Inc.) by parameter iteration using the three-parameter logistic function (3PL) and minimizing the least square residuals, essentially as described in Haanstra et al., 1985.

Toxicity data was fit with the three-parameter logistic function (3PL) using SigmaPlot version 12.0, (Systat Software, Inc., San Jose California USA). Multiple logit regression was carried out using Stata version 14.2 (StataCorp, College Station, Texas USA).

Bioaccumulation data were $\log$ transformed and fit with (multiple) linear regression using SigmaPlot version 12.0 after checking for Residual Normality (Shapiro-Wilk test $\mathrm{p}>0.05$ ) and Constant Variance (Levene's means test $\mathrm{p}>0.05$ ).

Differences in bioaccumulation patters between gills and digestive glands were tested by means of 1-way ANOVA (p <0.01) using Systat version 12.02 (Systat Software, Inc., San Jose California USA).

\section{Results}

\subsection{Characterization of AgNP}


181 Primary characterization (ultrapure water) of $5 \mathrm{~nm}$ AgNPs was performed elsewhere (Ribeiro et al.,

182 2014) showing tiny particles ranging in size from 3 to $8 \mathrm{~nm}$ and forming aggregates wrapped in an

183 organic layer (according to the manufacturer paraffin is used to protect particles and accounts for

$18418 \%$ in weight) which exhibits Z-average values (measured by dynamic light scattering) ranging

185 from 60 to $130 \mathrm{~nm}$ when diluted to $10 \mathrm{mg} \mathrm{L}^{-1}$ in MQ water. Despite a stable behavior in pure water,

186 the $5 \mathrm{~nm}$ AgNPs aggregated rapidly in seawater with faster kinetics at increasing concentrations

187 (Figure 1, Panel A). In longer times, $24 \mathrm{~h}$ and plus, $5 \mathrm{~nm} \mathrm{AgNP}$ tends to form micron-sized

188 aggregates (Figure 1, Panel B-D).

189

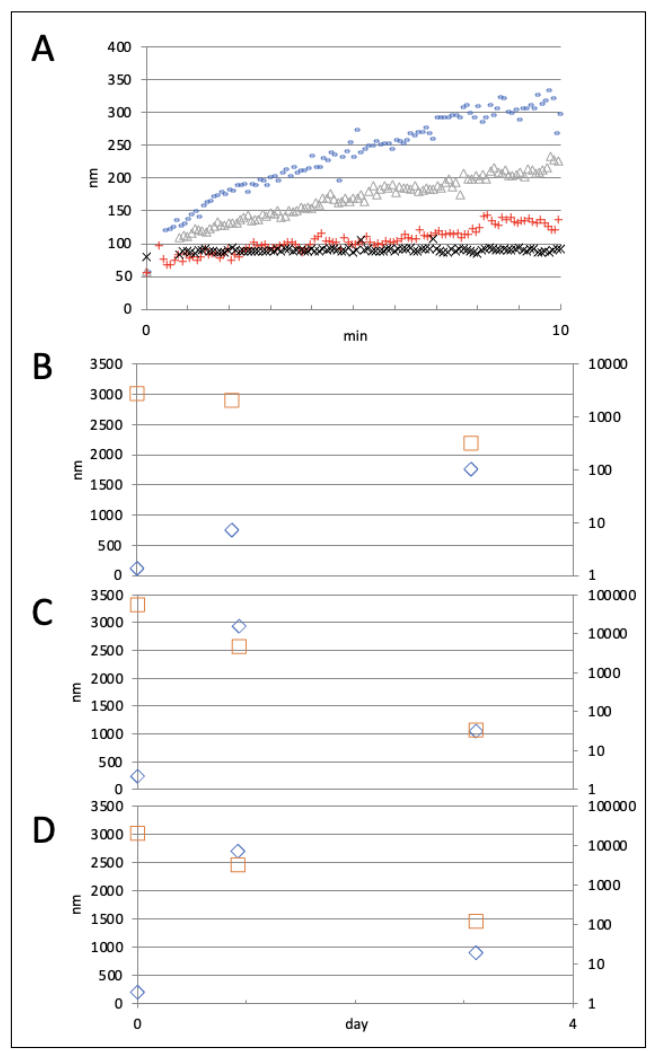

Figure 1 Pattern of 5 nm AgNP aggregation in seawater. Dynamic Light Scattering (DLS) analysis showed a consistent aggregation of $5 \mathrm{~nm}$ AgNPs with increasing hydrodynamic diameter (Z-average, $\mathrm{nm}$ ) across time. Panel A, sudden aggregation in ASW at nominal concentrations of $5 \mathrm{~nm} \mathrm{AgNP}\left(+, 1 \mathrm{mg} \mathrm{L}^{-1} ; \Delta, 5 \mathrm{mg} \mathrm{L}^{-1} ;-, 10 \mathrm{mg} \mathrm{L}^{-1} ; \mathrm{X}\right.$, ultrapure water). Panel B-D, effect of longer time (day) on aggregate size at 1,5 and $10 \mathrm{mg} \mathrm{L}^{-1}$. Micron sized AgNP aggregates appeared within $24 \mathrm{~h}$ (the renewal time in semi-static exposure) and showed to be unstable in seawater, as depicted by the count rate pattern. Legend, 田, Z-average, nm; 0 , Derived count rate, kilo counts s $\mathrm{s}^{-1}$. The phenomenon was time and concentration dependent. $50 \mathrm{~nm}$ AgNP could not be analysed by 
199 DLS analysis in seawater was unreliable for the $50 \mathrm{~nm} \mathrm{AgNP}$ due to instantaneous aggregation and 200 precipitation that at $1-10 \mathrm{mg} \mathrm{L}^{-1}$ was clearly visible to the naked eye (data not shown). Indeed, large 201 3-5-micron sized granules could be observed in SEM analysis of mussel gills sampled at the end of 202 the exposure $(96 \mathrm{~h})$ at different nominal exposure level $\left(0.1-10 \mathrm{mg} \mathrm{L}^{-1}\right)$. XRS analysis confirmed a 203 high amount of Ag in aggregates found juxtaposed to or trapped into mussel gills suggesting these 204 granules arose from primary $50 \mathrm{~nm}$ particles (Figure 2). Similar results but slightly smaller granules 205 were obtained with $5 \mathrm{~nm} \mathrm{AgNP}$ (data not shown).

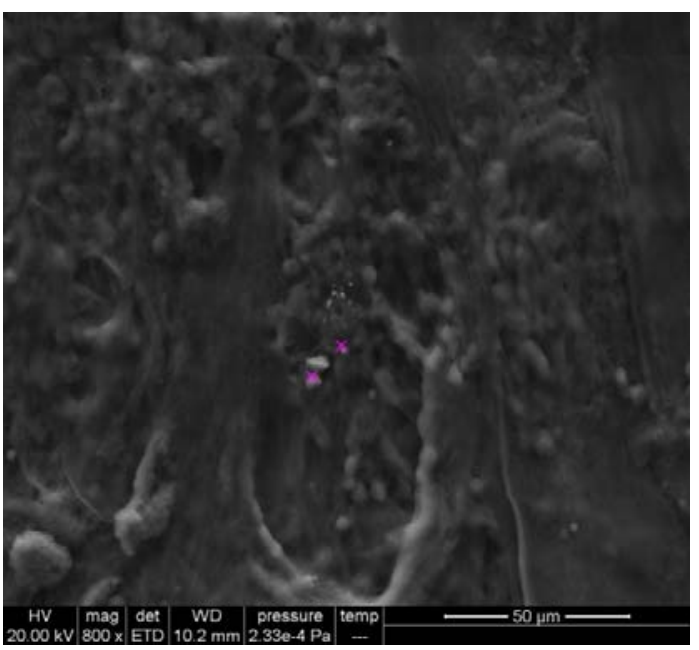

208 Figure 2. Scanning Electron Microscopy imaging of 50 nm AgNPs aggregates. A representative SEM photomicrograph depicts micron-sized aggregates (3-5 micron) arising from $50 \mathrm{~nm} \mathrm{Ag}$ primary particles (white arrows). Granules were found juxtaposed to ethanol fixed gills sampled from mussels after $96 \mathrm{~h}$ semi-static exposure at $0.1 \mathrm{mg}$ $\mathrm{L}^{-1} \mathrm{~d}$ (nominal level). Inlet panel, XRS analysis showing high Ag content in the granules (purple cross). Similar results were obtained for $5 \mathrm{~nm} \mathrm{Ag} \mathrm{ENPs} \mathrm{(data} \mathrm{not} \mathrm{shown).}$

\subsection{Modeling of silver persistence in seawater}

215 The variation of (total) silver concentration was measured in the water column during mussel 216 exposure to the two particulate forms of silver $-5 \mathrm{~nm} \mathrm{AgNP}$ or $50 \mathrm{~nm} \mathrm{AgNP-}$ or ionic silver 217 (administered in the form of nitrate). Water was sampled at 1, 4 and $24 \mathrm{~h}$ from the beginning of each exposure. The titer at $t_{0}$ was evaluated from the stock solution concentration. Five nominal exposure levels were used according to a $\log _{10}$ series. For the ionic form the nominal concentrations

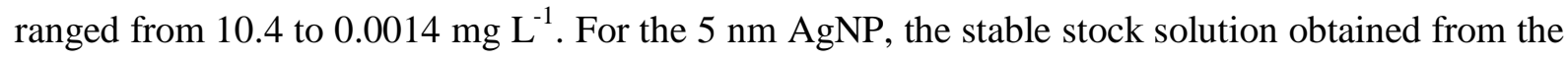


manufacturer showed a titer of $0.75 \pm 0.45 \mathrm{~g} \mathrm{~L}^{-1}$ due to the alkane-coating, therefore nominal exposure levels started from $7.5 \mathrm{mg} \mathrm{L}^{-1}$. For $50 \mathrm{~nm} \mathrm{AgNP}$ we, therefore, adjusted the concentration of the stock solutions to a similar level of the $5 \mathrm{~nm}$ AgNP. On average the stock solutions showed a exposures and their identifiers.

228 Figure 3 shows the persistence of total silver in seawater with the severest drop for the $50 \mathrm{~nm}$

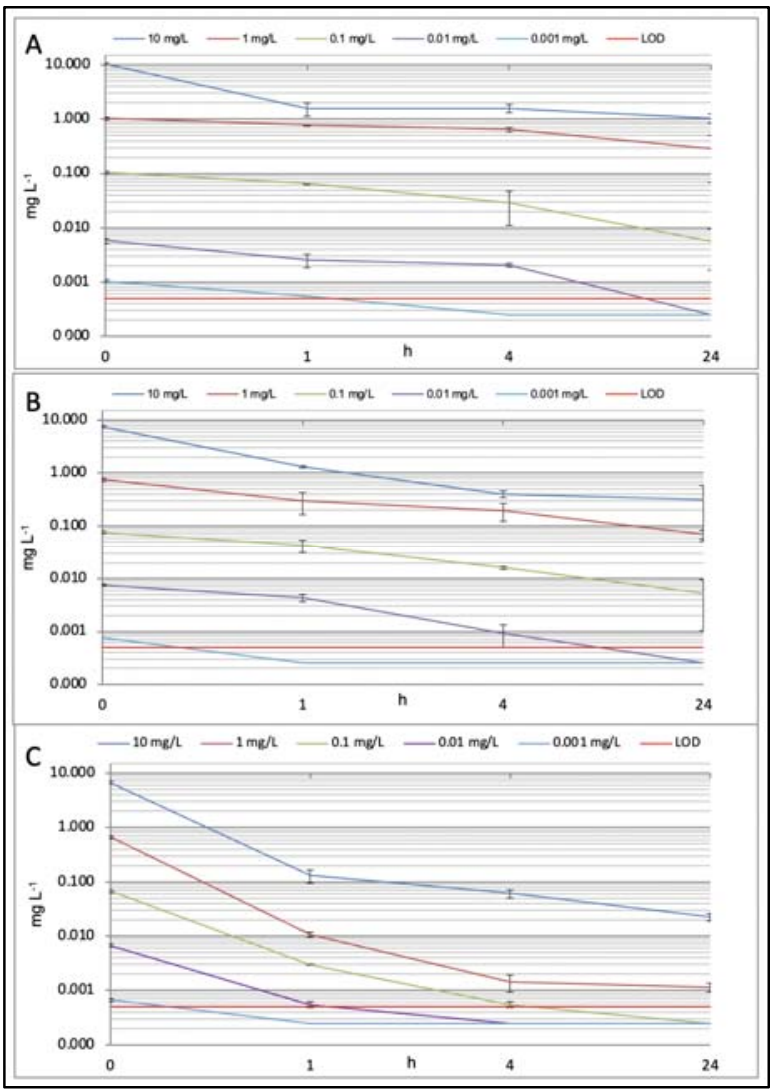

Figure 3. Persistence of $\mathbf{A g}$ in seawater. Total $\mathrm{Ag}$ concentration was measured in the water column across the $24 \mathrm{~h}$ renewal time for each nominal exposure level. Concentrations at $t_{0}$ were calculated from the titration of the stock solutions. Empirical Ag amounts were used to derive the integrated actual silver dose reported in Table 1. Shown are mean values +- $\mathrm{SD}(\mathrm{n}=4)$. The horizontal red line represents the LOD level for silver, $0.0005 \mathrm{mg} \mathrm{L}^{-1}$. In these graphs and in modelling, samples below LOD were assumed equal to $0.00025 \mathrm{mg} \mathrm{L}^{-1}$. Legend. Panel A, Ionic silver; Panel B, 5 nm AgNP; Panel C, 50 nm AgNP. 
239 Then, for each exposure conditions, we used a sigmoidal function to predict the silver concentration

240 (y) in water using time $(\mathrm{t})$ as the independent variable:

$241 \quad \mathrm{y}=\max /\left(1+(\mathrm{t} / \tau)^{\wedge} \mathrm{B}\right)$

242 where $\mathbf{y}$ represents the silver concentration $\left(\mathrm{mg} \mathrm{L}^{-1}\right), \mathrm{t}$ is time $(\mathrm{h}), \tau$ is a model parameter 243 representing the half-life of silver in the water column, B is a model parameter representing the 244 hillslope of the curve, Max is a model parameter (constant) representing the silver concentration at $245 \mathrm{t}_{0 .} \tau$ and $\mathrm{B}$ were parametrized to fit data into each model according to the least square residual using 246 a spreadsheet software (Table 1). The persistence models allowed a high accuracy prediction of the 247 the actual silver dose mussels were exposed to as the Area Under the Curve (AUC), i.e. the integral 248 of the logistic function in $0-24 \mathrm{~h}(24 \mathrm{~h}$ is the renewal time). Table 1 reports the predicted AUC 249 dosing per day $\left(\mathrm{AUC}_{0-24}\right)$ and per hour $\left(\mathrm{AUC}_{\mathrm{h}}\right)$ - the latter representing a proxy of the actual dose 250 level that can be useful for comparison with other works and external ecotoxicological datasets251 along with the model coefficients (Max, $\tau$ and B) and the outcome of the ANOVA F test. All 252 models for which a fair amount of data was available could be computed with a relatively low 253 standard error of the estimate (S) and therefore were highly significant.

Table1. Actual silver doses and persistence model parameters (logistic regression)

\begin{tabular}{|c|c|c|c|c|c|c|c|c|c|}
\hline Type & ID & $\operatorname{Max}\left(\operatorname{mg~L}^{-1}\right)$ & $\operatorname{AUC}_{0-24}\left(\mathrm{mg} \mathrm{d} \mathrm{L}^{-1}\right)$ & $\operatorname{AUC}_{h}\left(\mathrm{mg} \mathrm{h} \mathrm{L} \mathrm{L}^{-1}\right)$ & $\tau(\mathbf{h})$ & $\mathbf{B}$ & $\mathbf{S}$ & $\mathbf{R}^{2}$ & $\mathbf{P}$ \\
\hline $\mathrm{Ag}(+)$ & $10 \mathrm{mg} \mathrm{L}^{-1}$ & $1.04 \mathrm{E}+01$ & $2.66 \mathrm{E}+01$ & $1.11 \mathrm{E}+00$ & 0.01 & 0.32 & $4.46 \mathrm{E}-01$ & 0.98 & $1.3 \mathrm{E}-04$ \\
\hline $\mathrm{Ag}(+)$ & $1 \mathrm{mg} \mathrm{L}^{-1}$ & $1.04 \mathrm{E}+00$ & $1.26 \mathrm{E}+01$ & $5.26 \mathrm{E}-01$ & 9.54 & 0.51 & 4.42E-02 & 0.95 & $5.6 \mathrm{E}-04$ \\
\hline $\mathrm{Ag}(+)$ & $0.1 \mathrm{mg} \mathrm{L}^{-1}$ & $1.04 \mathrm{E}-01$ & $6.60 \mathrm{E}-01$ & $2.75 \mathrm{E}-02$ & 2.32 & 0.83 & $9.03 \mathrm{E}-03$ & $9.03 \mathrm{E}-03$ & $1.8 \mathrm{E}-03$ \\
\hline $\mathrm{Ag}(+)$ & $0.001 \mathrm{mg} \mathrm{L}^{-1}$ & $1.04 \mathrm{E}-02$ & $1.40 \mathrm{E}-02$ & $5.83 \mathrm{E}-04$ & 0.60 & 1.37 & $3.87 \mathrm{E}-04$ & 0.99 & 4.6E-05 \\
\hline $\mathrm{Ag}(+)$ & $0.001 \mathrm{mg} \mathrm{L}^{-1}$ & $1.04 \mathrm{E}-03$ & $1.40 \mathrm{E}-03$ & $5.83 \mathrm{E}-05$ & NA & NA & NA & NA & NA \\
\hline $\operatorname{Ag} 5 \mathrm{~nm}$ & $10 \mathrm{mg} \mathrm{L}^{-1}$ & $7.50 \mathrm{E}+00$ & $1.04 \mathrm{E}+01$ & $4.31 \mathrm{E}-01$ & 0.07 & 0.62 & $1.88 \mathrm{E}-01$ & 0.98 & $1.2 \mathrm{E}-05$ \\
\hline Ag $5 \mathrm{~nm}$ & $1 \mathrm{mg} \mathrm{L}^{-1}$ & $7.50 \mathrm{E}-01$ & $3.29 \mathrm{E}+00$ & $1.37 \mathrm{E}-01$ & 0.48 & 0.54 & $7.60 \mathrm{E}-02$ & 0.87 & $4.4 \mathrm{E}-03$ \\
\hline $\operatorname{Ag} 5 \mathrm{~nm}$ & $0.1 \mathrm{mg} \mathrm{L}^{-1}$ & $7.50 \mathrm{E}-02$ & $2.70 \mathrm{E}-01$ & $1.12 \mathrm{E}-02$ & 1.27 & 1.06 & $6.14 \mathrm{E}-03$ & 0.93 & $1.3 \mathrm{E}-03$ \\
\hline $\operatorname{Ag} 5 \mathrm{~nm}$ & $0.001 \mathrm{mg} \mathrm{L}^{-1}$ & $7.50 \mathrm{E}-03$ & $1.66 \mathrm{E}-02$ & $6.90 \mathrm{E}-04$ & 1.19 & 1.60 & $3.99 \mathrm{E}-04$ & 0.97 & $1.7 \mathrm{E}-04$ \\
\hline $\operatorname{Ag} 5 \mathrm{~nm}$ & $0.001 \mathrm{mg} \mathrm{L}^{-1}$ & 7.50E-04 & $1.66 \mathrm{E}-03$ & $6.90 \mathrm{E}-05$ & NA & NA & NA & NA & NA \\
\hline $\mathrm{Ag} 50 \mathrm{~nm}$ & $10 \mathrm{mg} \mathrm{L}^{-1}$ & $6.70 \mathrm{E}+00$ & $2.84 \mathrm{E}+00$ & $1.18 \mathrm{E}-01$ & 0.01 & 0.57 & $1.48 \mathrm{E}-01$ & 0.98 & $5.4 \mathrm{E}-06$ \\
\hline $\mathrm{Ag} 50 \mathrm{~nm}$ & $1 \mathrm{mg} \mathrm{L}^{-1}$ & $6.70 \mathrm{E}-01$ & $9.40 \mathrm{E}-02$ & $3.92 \mathrm{E}-03$ & 0.05 & 1.40 & 8.37E-04 & 0.98 & $5.4 \mathrm{E}-11$ \\
\hline $\mathrm{Ag} 50 \mathrm{~nm}$ & $0.1 \mathrm{mg} \mathrm{L}^{-1}$ & $6.70 \mathrm{E}-02$ & $1.98 \mathrm{E}-02$ & $8.25 \mathrm{E}-04$ & 0.11 & 1.37 & $5.60 \mathrm{E}-05$ & 0.98 & $1.0 \mathrm{E}-11$ \\
\hline $\mathrm{Ag} 50 \mathrm{~nm}$ & $0.001 \mathrm{mg} \mathrm{L}^{-1}$ & $6.70 \mathrm{E}-03$ & $1.98 \mathrm{E}-03$ & $8.25 \mathrm{E}-05$ & NA & NA & NA & NA & NA \\
\hline $\mathrm{Ag} 50 \mathrm{~nm}$ & $0.001 \mathrm{mg} \mathrm{L}^{-1}$ & $6.70 \mathrm{E}-04$ & $1.98 \mathrm{E}-04$ & $8.25 \mathrm{E}-06$ & NA & NA & NA & NA & NA \\
\hline
\end{tabular}
representing the constant parameter (maximum) of each model; $\mathrm{AUC}_{0-24}$, Area Under the Curve, the integral value obtained between 0-24 $\mathrm{h}$ from each persistence model, representing the predicted daily silver dose; $\mathrm{AUC}_{\mathrm{h}}, \mathrm{AUC}_{0-24}$ divided by 24 , a proxy of the silver exposure level; $\tau$, half-life of silver in the water column, a parameter of the regression model; $\mathrm{B}$, hillslope, the decay rate, a parameter 
of the regression model; S, standard error of the estimate; $\mathrm{R}^{2}$, squared $\mathrm{R}$ of the regression model; $\mathrm{P}$, probability of the insignificance of the predictors (ANOVA F test, p-value). NA, model cannot be computed. In this case, the AUC was calculated using $\tau$ and B from the model obtained for the next higher concentration.

96- $h$ acute toxicity test - mortality in water

265 Survival rate was evaluated after $96 \mathrm{~h}$ exposure to 5 or $50 \mathrm{~nm}$ AgNPs or ionic silver at the five dose

266 levels depicted in Table 1. Figure 4 shows a three parameters logistic regression model of survival

267 vs the predicted $\left(\mathrm{AUC}_{\mathrm{h}}\right)$ dose for each silver forms. All models were highly significant according to

268 ANOVA $(\mathrm{p}<0.001)$ and could predict toxicity with a low standard error of the estimate $(\mathrm{S})$,

269 ranging from 3 to 6\% (Table 2). Predicted toxicological endpoints (EC values) are presented in

270 Table 2 along with the model parameters. EC50 for ionic Ag was apparently lower than the values

271 obtained for the two nanoparticles $0.68 \mathrm{vs} 1.0 \mathrm{AUC}_{\mathrm{h}}\left(\mathrm{mg} \mathrm{h} \mathrm{L}^{-1}\right)$. To test the significance of such

272 difference and the possible dependence of survival on the silver form, we performed multiple

273 logistic regression analysis on the whole survival dataset (without control data) including dummy

274 variables for the classification of the type of silver. In this model, however, the type of silver

275 variables did not appear necessary to predict the survival outcome $(\mathrm{p}=0.711$ for $5 \mathrm{~nm} \operatorname{AgNP} ; \mathrm{p}=$ 2760.242 for $50 \mathrm{~nm} \mathrm{AgNP).}$ 

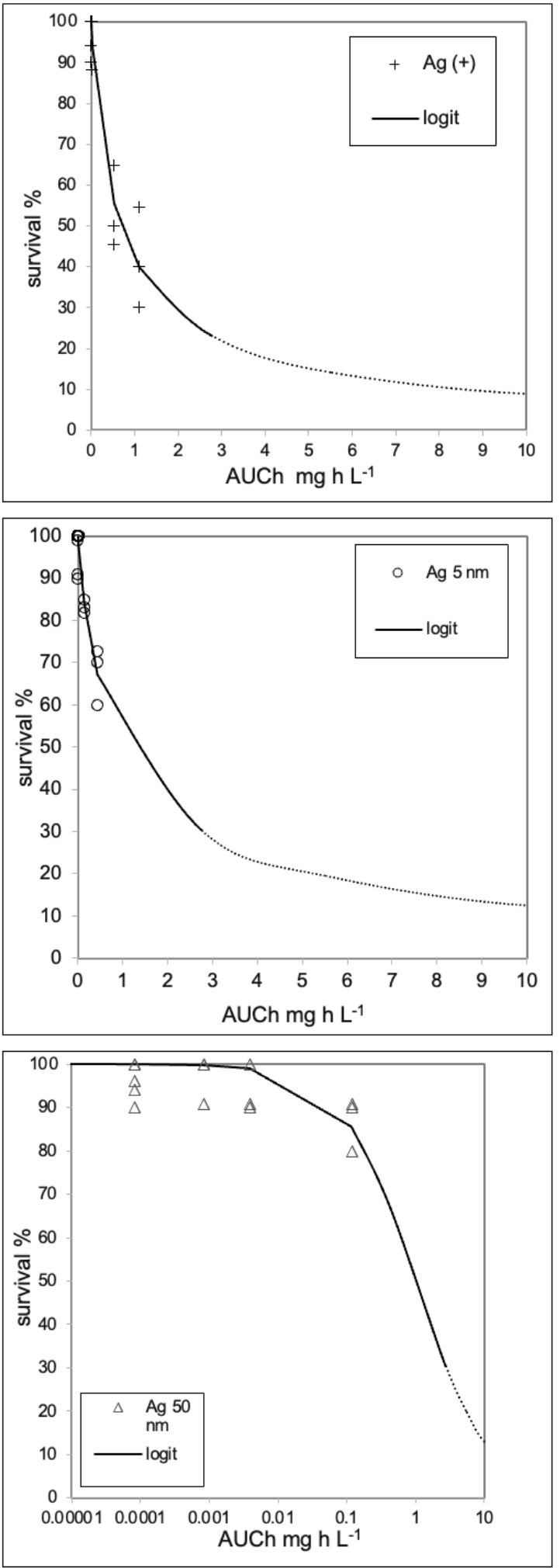

Figure 4. Cumulative toxicity curve for acute toxicity (survival rate). Logistic-regression models using the integrated silver dose as an independent variable. All models proved to be statistically significant by ANOVA. Details of statistics are presented in Table 2. 


\subsection{Chronic toxicity test - byssus adhesion}

284 Byssus adhesion was used as a proxy of chronic toxicity of silver ( $24 \mathrm{~h}$ exposure). Figure 5 shows

285 logistic regression of the effects of the three different silver forms on byssal performance, using the 286 predicted $\mathrm{AUC}_{\mathrm{h}}$ dose as an independent variable. All models were statistically significant ( $\mathrm{F}$ test, 287 ANOVA, $\mathrm{p}<0.001)$ although the two parameters $\mathrm{EC}_{50}$ and $\mathrm{B}$ could not be accurately computed for 288 the $50 \mathrm{~nm}$ AgNP (Table 2), most likely due to a lack of observations in the median range. Indeed, 289 the modelling indicated that ionic silver is much more effective on affecting byssal adhesion than 5 $290 \mathrm{~nm}$ and $50 \mathrm{~nm}$ AgNPs, and in fact, the predicted $\mathrm{EC}_{50}$ value is at least a magnitude order lower for 291 ionic silver. To test the statistical significance of such differences, multiple logit regression analysis was performed using the whole byssal adhesion dataset (control not exposed samples were excluded

293 from this analysis, $\left.\mathrm{N}=49, \mathrm{Chi}^{2}<0.00001\right)$ including dummy variables for silver types. This time, 294 the dependent variable adhesion (sensu strictu, its odds) can be more accurately predicted from a 295 combination of the independent variables $\mathrm{AUC}_{\mathrm{h}}$ and the type of silver dummy codes 296 (Supplementary Table 1).

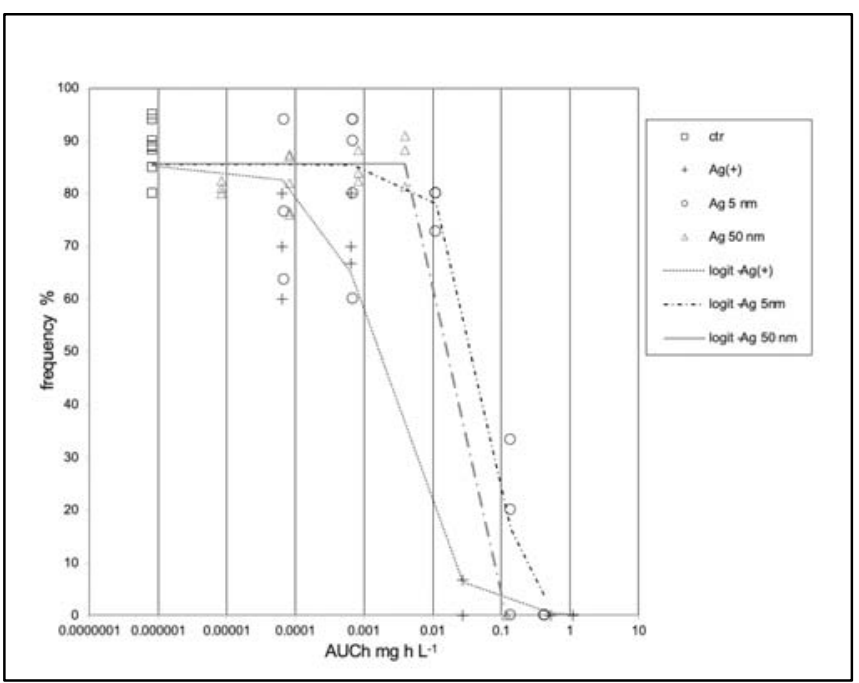

Figure 5. Cumulative toxicity curve for byssus adhesion. Adhesion was used as a proxy of byssus functionality. Shown are logistic-regression models for adhesion obtained using the integrated silver dose as an independent variable. Binomial data were percentualized and logistic regression. The solid line represents an additional model built with all data(see explanation in text). All models proved to be statistically significant by ANOVA. Details of statistics are presented in Table 1 . 
Table 2. Logistic regression of silver toxicity: endpoints and model coefficients.

\begin{tabular}{|c|c|c|c|c|c|c|c|c|c|c|c|c|}
\hline Type & Effect & EC1 & EC5 & EC10 & EC20 & EC50 & SE & $\mathbf{P}$ & B & $\operatorname{Max}(\%)$ & $\mathbf{S}$ & $\overline{\mathbf{R}^{2}}$ \\
\hline $\mathrm{Ag}(+)$ & survival & $3.20 \mathrm{E}-03$ & $2.20 \mathrm{E}-02$ & $5.30 \mathrm{E}-02$ & $1.40 \mathrm{E}-01$ & $6.80 \mathrm{E}-01$ & $8.00 \mathrm{E}-02$ & $<0.0001$ & 0.88 & 99.4 & 5.88 & 0.94 \\
\hline Ag $5 \mathrm{~nm}$ & survival & $4.20 \mathrm{E}-03$ & $3.00 \mathrm{E}-02$ & 7.30E-02 & $1.90 \mathrm{E}-01$ & $1.00 \mathrm{E}+00$ & $2.00 \mathrm{E}-01$ & $<0.0001$ & 0.88 & 99.3 & 3.43 & 0.91 \\
\hline $\mathrm{Ag} 50 \mathrm{~nm}$ & survival & $3.90 \mathrm{E}-03$ & $2.90 \mathrm{E}-02$ & $7.10 \mathrm{E}-02$ & $1.90 \mathrm{E}-01$ & $1.00 \mathrm{E}+00$ & $4.20 \mathrm{E}-01$ & 0.02 & 0.92 & 97.7 & 4.17 & 0.70 \\
\hline $\mathrm{Ag}(+)$ & adhesion & $1.96 \mathrm{E}-05$ & $1.05 \mathrm{E}-04$ & $2.24 \mathrm{E}-04$ & $5.12 \mathrm{E}-04$ & $2.10 \mathrm{E}-03$ & $9.00 \mathrm{E}-04$ & 0.013 & 1.17 & 85.3 & 7.64 & 0.96 \\
\hline Ag $5 \mathrm{~nm}$ & adhesion & $2.53 \mathrm{E}-03$ & 7.54E-03 & $1.24 \mathrm{E}-02$ & $2.12 \mathrm{E}-02$ & $5.30 \mathrm{E}-02$ & $1.60 \mathrm{E}-02$ & 0.003 & 1.51 & 85.6 & 10.09 & 0.91 \\
\hline $\operatorname{Ag} 50 \mathrm{~nm}$ & adhesion & 2.01E-02 & 2.04E-02 & $2.06 \mathrm{E}-02$ & $2.07 \mathrm{E}-02$ & $2.10 \mathrm{E}-02$ & NA & 0.987 & 102 & 85.7 & 5.19 & 0.97 \\
\hline
\end{tabular}

Shown are: Type, silver form; Effect, acute $96 \mathrm{~h}$ survival or chronic $24 \mathrm{~h}$ byssal adhesion toxicity test; ECx, calculated endpoints; EC50, a parameter of the regression model; SE, standard error of EC50; P, t-test p-value of EC50 as a model parameter; B, hillslope, a parameter of the regression model; Max (\%), the constant parameter of the regression model; $\mathrm{S}$, standard error of the estimate; $\mathrm{R}^{2}$, squared $\mathrm{R}$ of the regression model. All models were significant (F-test, ANOVA, $\mathrm{p}<0.001)$; t-test on the predictors EC50 and B failed in byssal adhesion for $50 \mathrm{~nm} \mathrm{AgNP.} \mathrm{All} \mathrm{ECx} \mathrm{are} \mathrm{reported} \mathrm{as} \mathrm{AUC} \mathrm{h}_{\mathrm{h}}$ in $\mathrm{mg} \mathrm{h} \mathrm{L}^{-1}$. NA, cannot be computed.

\subsection{Silver uptake in mussel body burden.}

Silver burdens were evaluated in mussel soft tissues after $96 \mathrm{~h}$ exposure. Internal silver concentrations could be predicted using a linear regression models with logarithmic transformations (log-log model) with the total (96 h) AUC dose level as the independent variable (Figure 6). The three models obtained displayed similar slopes, suggesting that the uptake is influenced by the silver concentration in a similar fashion. However, the models have different constants, that would indicate different uptake efficiencies, for 5 and $50 \mathrm{~nm} \mathrm{AgNP,} \mathrm{the} \mathrm{latter} \mathrm{showing} \mathrm{the} \mathrm{lowest} \mathrm{value.}$

To test the significance of such differences, multiple linear regression analysis was performed on the whole uptake dataset using silver type dummy codes as additional independent variables (controls were excluded from the analysis). The internal silver concentration could be predicted with high confidence $\left(\mathrm{N}=55 \mathrm{~F}\right.$ test, ANOVA, $\left.\mathrm{p}<0.001, \mathrm{R}^{2} 0.80 \%\right)$ from a linear combination of the independent variables $\mathrm{AUC}_{96 \mathrm{~h}}$ (t-test $\left.\mathrm{p}<0.001\right)$, and dummy codes for silver types, $5 \mathrm{~nm} \mathrm{AgNP}$ (p $=0.018)$ and $50 \mathrm{~nm} \operatorname{AgNP}(\mathrm{p}<0.001)$ (net of a constant). The two dummy variables introduced a negative correction on the log internal concentration respectively of -0.38 and -0.75 fold per each $\log -\mathrm{AUC}_{96 \mathrm{~h}}$ unit increase of the silver dose of 5 and $50 \mathrm{~nm}$ AgNP (Supplementary Table 2). 


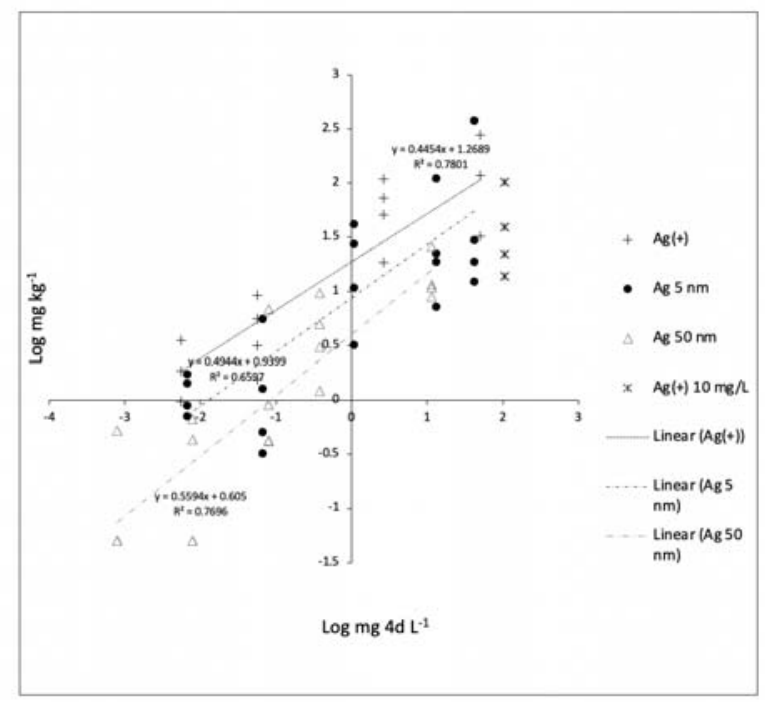

Figure 6. Ag burdens in mussel soft tissues $\left(96 \mathbf{~ h}\right.$ exposure). Shown are linear regression models $\left(\log _{10}-\log _{10}\right.$ transformation) using the $96 \mathrm{~h}$ integrated silver dose (AUC 4d) as independent variable (data of $\mathrm{Ag}^{+}$at the highest dose level $-10 \mathrm{mg} \mathrm{L}^{-1} \mathrm{nominal}$ concentration- are shown but were excluded from the analysis to avoid any possible bias due to the high mortality rate observed. All models proved to be statistically significant (ANOVA), $\mathrm{P}$ value $<0.001$. Control not exposed samples were not considered in these analyses.

333 We also looked at the differential accumulation of silver in the two main bioaccumulating organs,

334 gills and digestive gland after $96 \mathrm{~h}$ exposure to the nominal dose of $1 \mathrm{mg} \mathrm{L}^{-1}$ (Table 1).

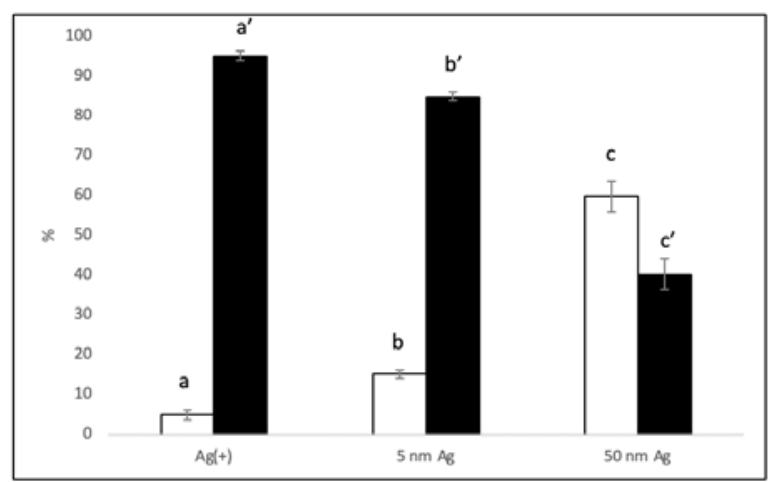

Figure 7. Ag distribution in soft tissues. Silver was evaluated in two main target tissues, gills (solid bars) and digestive gland (open bars) after $96 \mathrm{~h}$ exposure to ionic silver $\left(\mathrm{Ag}^{+}\right), 5 \mathrm{~nm}$ or $50 \mathrm{~nm}$ AgNPs. Shown are the average \% distributions in tissues found from three independent experiments at $1 \mathrm{mg} \mathrm{L}^{-1}$ nominal exposure level. Each experiment used the median value obtained from 8 specimens. Very similar trend was observed also at $0.1 \mathrm{mg} \mathrm{L}^{-1}$ (data not shown). A different superscript letter indicates a statistically significant difference (ANOVA, $\mathrm{p}<0.0001, \mathrm{~N}=3$ ). 


\section{Discussion}

347 In this study we provided a framework to address the hazard of AgNPs in the common marine 348 bioindicator species $M$. galloprovincialis Lam, using ionic silver as a reference for toxicity. We

349 embedded two simple and inexpensive tests - 96h acute mortality test and byssus adhesion- in a 350 robust statistical context making extensive use of regression analysis to -first- predict the most 351 accurate exposure levels accounting for silver variation across time and then to test the dependence 352 of toxicity on the actual dose level and the silver form.

353 A sudden precipitation of silver aggregate with an overall drop of the silver titer was often reported 354 in previous silver nanoparticle exposures in seawater systems (Gomes et al., 2013; Gomes et al., 355 2014; Ale et al., 2018). Salinity, in fact, is the major factor affecting zeta potential, the electrostatic 356 potential near the particle surface that is a measure of the magnitude of repulsion or attraction 357 between particles (Hochella et al., 2012). In case of ionic silver (provided to the system in form of 358 nitrate) the concentration is expected to remain longer constant due to the formation of complex 359 ions with chloride and hydroxide (Luoma et al., 1995; Santore and Driscoll, 1995; Fabrega et al., 360 2011). To this end, a persistence model based on the three parameters sigmoidal (logistic) 361 regression function (3PL) was used to fit chemical data -total silver- obtained in time series across $3620-24 \mathrm{~h}$, the renewal time in our semi-static exposures. Despite the logistic function is typically used 363 to predict binary data, this model has been successfully and extensively used in toxicology as well 364 as enzymology to describe continuous data by means of parameter iteration minimizing the least 365 square residuals rather than by the maximum likelihood estimation as in canonical logistic models 366 (Haanstra et al., 1985; Jonker et al., 2005). These equations were used to determine the actual silver 367 dose mussels were exposed to as to the Area Under the Curve $\left(\mathrm{AUC}_{0-24}\right)$ rendering in general very 368 good predictions and very low standard errors of the estimation (Table 1). 3PL represents a good 369 model since it relies on a constant that in this case is the maximum silver concentrations in the 370 water column -easily determined from the known amount added to water at time zero; the half-live $371(\tau)$ of silver concentration in the water column and a hillslope representing the decay rate. As a rule 
372 of thumb, $\tau$ values associated to AgNPs were often inversely correlated with the initial silver

373 concentration, suggesting the occurrence of concentration dependent aggregation and precipitation

374 processes (Table 1). Moreover, the stability of $5 \mathrm{~nm} \mathrm{AgNP}$ was much higher than that of larger 50

$375 \mathrm{~nm}$ particles. In fact, their $\tau$ values, typically, displayed differences higher than one magnitude

376 order. As an example, at $0.1 \mathrm{mg} \mathrm{L}^{-1}$ (nominal) level, $\tau_{5 \mathrm{~nm}}$ and $\tau_{50 \mathrm{~nm}}$ were $1.27 \mathrm{~h} \mathrm{vs} 0.11 \mathrm{~h}$,

377 respectively. At a higher level, $1 \mathrm{mg} \mathrm{L}^{-1}, 0.48 \mathrm{~h}$ vs $0.05 \mathrm{~h}$, respectively. At $10 \mathrm{mg} \mathrm{L}^{-1}$ level, the

378 precipitation process was instantaneous as argued by the $\tau$ values, respectively of $0.07 \mathrm{~h}$ and $0.01 \mathrm{~h}$.

379 Half-life for the $5 \mathrm{~nm} \mathrm{Ag}$ particles could be also computed at $0.01 \mathrm{mg} \mathrm{L}^{-1}$ level, rendering a $\tau$ equal

380 to $1.19 \mathrm{~h}$. As expected, ionic silver showed the highest persistence in seawater thanks to the

381 formation of complex ions, however, at the highest nominal concentration of $10 \mathrm{mg} \mathrm{L}^{-1}$ was clearly

382 fairly above the saturation limit $(\tau=0.01 \mathrm{~h})$. In general, at the lowest nominal exposure

383 concentration levels, data could not be fitted, since total Ag was below the detection limit of the

384 technique (LOD, $0.0005 \mathrm{mg} \mathrm{L}^{-1}$ ). In those cases, the AUC was derived using the model parameters

385 obtained for the next higher concentration. Along with $\mathrm{AUC}_{0-24 \mathrm{~h}}$ we introduced a linear

386 transformation of it, i.e. AUC per $\mathrm{h}\left(\mathrm{AUC}_{\mathrm{h})}\right.$ that would ideally represent a proxy of the actual silver

387 concentration as if this were constant in real scenarios, for example by imagining a continuous input

388 from rivers and discharges to the marine environment.

389 Once obtained a reliable estimation of the actual exposure levels, we initially used AUC as the

390 unique independent variable to predict silver acute, chronic toxicity as well as silver uptake in

391 mussel soft tissues. For toxicity tests, we again employed the 3PL model that provided accurate

392 predictions, as judged by the overall low standard error of the estimate (Table 2). In a second step,

393 we tested the model improvement by means of multiple regression accounting for the contribution

394 of the different silver form. To this aim, we introduced dummy variables representative of the two

395 AgNP types (ionic silver as to reference), excluding control not-exposed reference samples from the

396 analysis. Despite a slight lower EC50 for ionic silver (Table 2), apical effects, however, could be

397 merely explained by the actual (total) silver concentration in the water column as the two new 
variables were not significant (see Section 3.2) and did not provide a consistent error reduction to 399 model fitting.

400 By contrast, a model improvement was determined for byssal adhesion after the introduction of 401 dummy codes for the silver types. Multiple logit regression introduced a statistically significant 402 positive correction on adhesion by a factor 3.66 and 4.65 per each $\mathrm{AUC}_{\mathrm{h}}$ unit increase, respectively 403 for $5 \mathrm{~nm}$ and $50 \mathrm{~nm}$ AgNP (as to ionic silver as a reference). This finding poses for an undoubtedly 404 harsher effects of ionic silver over nanoparticles that depends frankly on the silver form.

405 Silver uptake (bioaccumulation) in mussel body burdens was also measured and modelled as a 406 function of the AUC dose. In this case, we could apply (multiple) linear regression analysis as all 407 conditions for ordinary least square could be satisfied after log-log transformation of the variables. This analysis allowed to infer statistically significantly different uptake kinetics for the three silver forms into mussel soft tissues. AgNPs were, in general, less prone to uptake than ionic silver and thanks to the predicted AUC levels, this difference can be explained through the preferential uptake 411 route of ionic silver vs NPs (Figure 7). The silver amounts found in soft tissues can be correlated 412 with some previous studies, that however are rather heterogeneous. In a study employing a 413 commercial preparation containing AgNPs provided at the nominal level of 0.001 and $0.010 \mathrm{mg} \mathrm{L}^{-1}$, 414 after $96 \mathrm{~h}$ Ale et al. (2019) found 0.49 and $4.93 \mathrm{mg} \mathrm{kg}^{-1}$ (dry weight) in mussel soft tissues, which 415 appear comparable with the range found for $5 \mathrm{~nm}$ AgNP at same nominal levels, 0.7-1.7 and 0.3-5.6 $416 \mathrm{mg} \mathrm{kg}^{-1}$. Gomes et al. (2014) -who used the same nominal level of $0.010 \mathrm{mg} \mathrm{L}^{-1}$ of either ionic 417 silver or $100 \mathrm{~nm}$ AgNP in 3-15-day exposure- found a comparable bioaccumulation pattern for gills 418 but significant higher silver amounts were found also in the digestive gland, in particular for silver 419 nitrate. Jemeno-Romero et al., 2017 did not find meaningful silver accumulation pattern in body 420 burdens of mussels exposed for 3 days to either ionic Ag or maltose-stabilized AgNPs (0.00075, $4210.075,0.750 \mathrm{mg} \mathrm{L}^{-1}$ ) of various size, but they justified it for the high mortality rate experienced. 422 They could, however, highlight protein-associated metal deposits in the digestive gland (but not 423 gills, mantle and gonads) by means of auto-metallography. The same research group claimed that 
424 dietary exposure is a much better vehicle for silver bioaccumulation (Duroudier et al., 2019;

425 Duroudier et al., 2021).

426 There are possible explanations accounting for the difference observed between the effects of silver

427 on survival and adhesion. First, the two tests relied on different lengths, $96 \mathrm{~h}$ and $24 \mathrm{~h}$, respectively.

428 Then, apical effects such as mortality are a translation of the complex result of molecular initiating

429 and key events as well as their interactions. Previous studies suggested reactive oxygen species

430 formation, protein oxidation (carbonylation), protein sulfhydryl depletion, DNA damage and

431 genotoxicity, that are compatible with an overall electrophilicity of heavy metals ions towards

432 nucleophilic atoms (S, N, O) of biological macromolecules (Gomes et al., 2013; Gomes et al., 2014;

433 Katsumiti et al., 2015; Bouallegui et al., 2018; Duroudier et al., 2021). Proteomic studies indicated

434 also the involvement of moonlight proteins such super oxide dismutase (SOD), glyceraldehyde 3-

435 phosphate dehydrogenase (GAPDH), malate dehydrogenase as well as other molluscan specific

436 features (Duroudier et al., 2019).

437 For what concerns the effects on byssal adhesion our data demonstrated that adhesive plaques were

438 clearly highly sensitive to silver, in particular the ionic form appeared much more effective than

439 AgNPs. Byssal adhesion relies on a bunch of catecholamines-rich proteins, in particular their

440 modified amino acid 3,4-dihydroxyphenyl-L-alanine (L-DOPA). In Mytilus congeners in fact, this

441 modified amino acid is able to establish interactions with natural surfaces and the protein most

442 involved is, of course, mussel foot protein-3 (mfp-3) existing in numerous variants (Zhao et al.,

443 2006). Byssal adhesion relies on the reducing state of L-DOPA residues, hence another cysteine-

444 rich mussel foot protein, mfp-6, acts as an interprotein thiol-mediated redox modulator able to

445 restore the functionality of the corrupted (sensu oxidized) adhesive plaque proteins (Yu et al.,

446 2011). This would be a mechanism requiring silver uptake / transport in the mussel foot where

447 adhesive proteins are synthetized, that although we did not verify, it is likely to occur. To this end,

448 reduced thiols (free-thiol oxidation) were reported in mussels tissues exposed to $<50 \mathrm{~nm}$ AgNP for

449 just 12h (Bouallegui et al., 2018). We can argue, nonetheless, a second mechanism for byssal 
450

adhesion impairment, as functional silky mussel threads establish histidine-mediated intermolecular binding of metals such as zinc at the level of the collagenous stalk (Qin and White, 1998) as well as metal-catecholate complexes at the adhesive plaque matrix protein mfp-1 (Xu, 2013). In this regard, there are clear roles of coordination state and metal types whereas Ag ions -being particularly electrophilic- might further destabilize byssal threads before internalization in a straightforward mechanism from the external. Ionic silver would be immediately available to impair byssal adhesion while AgNPs will require prior dissolution. Despite we did not accurately evaluate the dissolution rate in the water column across time, we gathered preliminary data by ultracentrifugation that suggest a fair amount of soluble silver in the water column. Averaging the three highest nominal exposure levels of $5 \mathrm{~nm} \mathrm{AgNP}$, the soluble silver fraction was $14.1 \pm 2.9 \%$, $37.6 \pm 5.0 \%$ and $60.3 \pm 14.5 \%$ of the total amount found in the water column, respectively at 1,4

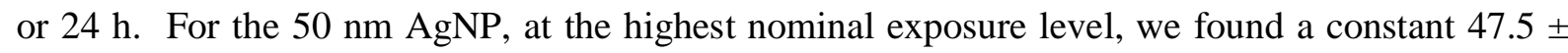
$1.5 \%$ soluble vs total silver with no time effects. Some authors reported silver solubilization rates from AgNP in seawater as a function of time. This process seems to be influenced by coating, size and salinity. At $24 \mathrm{~h}$ (the renewal time in this work) Katsumiti et al. (2015) counted an overall 9\% soluble silver from maltose coated AgNP of various sizes. Schiavo et al., 2017 reported 20\% from 5 nm PVP/PEI coated particles but only 1.5\% for uncoated $47 \mathrm{~nm} \mathrm{AgNP;} \mathrm{AgNP;} \mathrm{Sikder} \mathrm{et} \mathrm{al.,} 2018$ again for PVP AgNP at $30 \mathrm{ppt}$ salinity reported a ratio of $0.019 \% \mathrm{~h}^{-1}$, rendering up to $45 \%$ soluble silver in 24 h. Gomes et al. (2014) reported a 44\% dissolution of < $100 \mathrm{~nm}$ AgNP after only $12 \mathrm{~h}$.

One of the main pathways of metal ion entry into mussels is passive diffusion across the gill epithelium (George and Pirie, 1980; Scholz, 1980; Carpene and George, 1981; Everaarts, 1990; Soto et al., 1996). Our data on silver uptake dynamics in gills and digestive gland after $96 \mathrm{~h}$ exposure indicated the former route is almost exclusive for ionic silver (95\%), dominant for $5 \mathrm{~nm}$ AgNP (85\%) and even for larger $50 \mathrm{~nm} \mathrm{AgNP} \mathrm{(40 \% )} \mathrm{(Figure} \mathrm{7).} \mathrm{It} \mathrm{should} \mathrm{be} \mathrm{said} \mathrm{that} \mathrm{in} \mathrm{long-term}$ exposure to ionic silver, in contrast to other heavy metals, silver did not accumulate in the digestive tubules within lysosomes but in the basement membranes and tissue macrophages in some forms 
associated to sulphur (George et al., 1986) whilst AgNP -in particular larger ones- are more readily

477 available to the digestive tissues (this work; Gomes et al., 2014; Duroudier et al., 2019; Duroudier

478 et al., 2021). Overall, this body of evidence may explain the existence of a double contribution to

479 apical toxicity of AgNP -i.e. via gills and digestive gland by a Trojan Horse effect.

480 To our knowledge this is the first time in marine nanotoxicology the actual exposure levels, i.e. the

481 AUC, were reconstructed and systematically related to the toxicological outcomes. Unbiased

482 ecotoxicological endpoints were, hence, calculated for acute and chronic toxicity. These values are

483 not affected by the persistence of silver in seawater and are corrected for the actual metal

484 bioavailability / readiness to uptake. This approach allowed us to evaluate the genuine potential of

485 AgNP toxicity and make a reliable comparison with the ionic form. For acute toxicity (survival), we

486 showed comparable LC50 values between ionic and particulate silver. In a previous in vitro study,

487 larger differences were reported ranging between 5 to 21 folds for both hemocytes and gill cells

488 (Katsumiti et al., 2015). In case of chronic toxicity, also our data showed larger disparities between

489 the particulate and ionic silver forms for which we argued mechanistic explanations involving a

490 deferral of silver ion bioavailability dissolving from nanoparticles. Auguste et al. (2018), likewise,

491 essentially attributed to a very low dissolution rate of their $47 \mathrm{~nm}$ AgNP the 20-fold change

492 observed between $\mathrm{EC} \mathrm{0}_{48 \mathrm{~h}}$ values for developmental defects of mussel larvae. They, however, did

493 not consider any sedimentation / precipitation process, therefore, they might have underestimated

494 AgNP toxicity. On the basis of the unbiased ecotoxicological endpoints obtained in our study, it

495 appears clear that in the marine environment the Risk Quotient (i.e. PEC/NOAEL ratio) for nano-

496 silver is too far from providing a level of concern for nano-silver, at least in regard to a chronic risk.

497 Regressed unbiased EC1 values (surrogate NOAELs) obtained in mussels acute or chronic toxicity

498 tests were, in fact, in the range of a few ppb for AgNPs (least value, $2.5 \mathrm{ppb}$ for $5 \mathrm{~nm}$ AgNP in

499 chronic test) and down to $20 \mathrm{ppt}$ for ionic silver (Table 2), whereas the Predicted Environmental

500 Concentration (PEC) for nano-silver is as low as $1 \mathrm{pg} \mathrm{L}^{-1}$ (Gottschalk et al., 2015; Giese et al.,

501 2018). Even considering a worse case scenarios of $5 \mathrm{ng} \mathrm{L}^{-1}$ silver nanoparticle transported by large 
502 rivers such as the Rhine (Markus et al., 2016) to an estuarine environment, this would render a 503 negligible RQ value. More attention, however, should be given to the possible contribution of 504 AgNP to the total silver loads from punctual sources, such as discharges and estuaries where the 505 environmental silver concentrations might considerably shift up reaching higher level of concern.

\section{Acknowledgments}

509 This work was financially supported by the NanoFATE, Project CP-FP 247739 (2010-2014) under

510 the 7th Framework Programme of the European Commission (FP7-NMP-ENV-2009, Theme 4); 511 www.nanofate.eu.

\section{References}

1. Ale, A., Rossi, A.S., Bacchetta, C., Gervasio, S., de la Torre, F.R., Cazenave, J., 2018. Integrative assessment of silver nanoparticles toxicity in Prochilodus lineatusfish. Ecological Indicators. 93, 1190-1198.

2. Ale, A., Liberatori, G., Vannuccini, M. L., Bergami, E., Ancora, S., Mariotti, G., et al. 2019. Exposure to a nanosilver-enabled consumer product results in similar accumulation and toxicity of silver nanoparticles in the marine mussel Mytilus galloprovincialis. Aquatic nanosilver on Mytilus galloprovincialis hemocytes and early embryo development. Aquatic Toxicology. 203, 107-116. 
4. Baun A., Hartmann N.B., Grieger K., Kusk K.O., 2008. Ecotoxicity of engineered nanoparticles to acquatic invertebrates: a brief review and recommendations for future toxicity testing. Ecotoxicology. 17, 387-395

5. Beyene, H. D., Werkneh, A. A., Bezabh, H. K., Ambaye, T. G., 2017. Synthesis paradigm and applications of silver nanoparticles (AgNPs), a review. Sustainable materials and technologies. 13, 18-23.

6. Bouallegui, Y., Younes, R. B., Oueslati, R., Sheehan, D., 2018. Role of endocytotic uptake routes in impacting the ros-related toxicity of silver nanoparticles to Mytilus galloprovincialis: a redox proteomic investigation. Aquatic Toxicology. 200, 21-27.

7. Bourdineaud, J. P., Štambuk, A., Šrut, M., Radić Brkanac, S., Ivanković, D., Lisjak, D., et al., 2021. Gold and silver nanoparticles effects to the earthworm Eisenia fetida-the importance of tissue over soil concentrations. Drug and chemical toxicology. 44(1), 12-29. as unique target group for nanoparticles toxicity. Marine Environmental Research. 76, 1621.

9. Carpene, E., George, S.G., 1981. Absorption of cadmiumby gills of Mytilus edulis (L.). Molecular Physiology. 1, 2334.

10. Chen, D., Qiao, X., Qiu, X., Chen, J., 2009. Synthesis and electrical properties of uniform silver nanoparticles for electronic applications. Journal of materials science. 44(4), 10761081.

11. Darlington T.K., Neigh A.M., Spencer M.T., Nguyen O.T., Oldenburg S.J., 2009. Nanoparticle characteristics affecting environmental fate and transport through soil. Environ. Toxicol. Chem. 28, 1191-1199

12. Diez-Ortiz, M., Lahive, E., George, S., Ter Schure, A., Van Gestel, C. A., Jurkschat, K., Spurgeon, D. J., 2015. Short-term soil bioassays may not reveal the full toxicity potential for 
nanomaterials; bioavailability and toxicity of silver ions (AgNO3) and silver nanoparticles to earthworm Eisenia fetida in long-term aged soils. Environmental pollution, 203, 191-198. al., 2019. Changes in protein expression in mussels Mytilus galloprovincialis dietarily exposed to PVP/PEI coated silver nanoparticles at different seasons. Aquatic Toxicology. 210, 56-68.

14. Duroudier, N., Katsumiti, A., Mikolaczyk, M., Schäfer, J., Bilbao, E., Cajaraville, M. P., 2021. Cell and tissue level responses in mussels Mytilus galloprovincialis dietarily exposed to PVP/PEI coated Ag nanoparticles at two seasons. Science of the Total Environment. 750, 141303.

15. Everaarts, J.M., 1990. Uptake and release of Cd in various organs of the common mussel, Mytilus edulis (L.). Bulletin Environmental Contamination Toxicology. 45, 560-567. behaviour and effects in the aquatic environment. Environmental International. 37, 517-531

17. George, S.G., Pirie, B.J.S., 1980. Metabolism of zinc in the mussel, Mytilus edulis (L.): a combined ultrastructural and histochemical study. J. Mar. Biol. Ass. UK. 60, 575-590. ultrastructural observations of long-term silver accumulation in the mussel, Mytilus edulis. Marine Environmental Research. 18(4), 255-265. Gottschalk, F., 2018. Risks, release and concentrations of engineered nanomaterial in the Genotoxicity of copper oxide and silver nanoparticles in the mussel Mytilus galloprovincialis. Marine Environmental Research. 84, 51-59 

Bebianno, M. J., 2014. Effects of silver nanoparticles exposure in the mussel Mytilus galloprovincialis. Marine environmental research. 101, 208-214.

22. Gottschalk, F., Lassen, C., Kjoelholt, J., Christensen, F., Nowack, B., 2015. Modeling flows and concentrations of nine engineered nanomaterials in the Danish environment. International journal of environmental research and public health. 12(5), 5581-5602.

23. Haanstra, L., Doelman, P., Voshaar, J.H.O., 1985. The use of sigmoidal dose response curves in soil ecotoxicological research. Plant Soil. 84, 293-297.

24. Hochella Jr M.F., Aruguete D., Kim B., Madden A.S., 2012. Naturally occurring inorganic nanoparticles: general assessment and a global budget for one of earth's last unexplored geochemical components. In: Nature's Nanostructures. Pan Stanford Publishing, Australia. $1-42$

25. Jimeno-Romero, A., Bilbao, E., Izagirre, U., Cajaraville, M.P., Marigómez, I., Soto, M., 2017. Digestive cell lysosomes as main targets for Ag accumulation and toxicity in marine mussels, Mytilus galloprovincialis, exposed to maltose-stabilised Ag nanoparticles of different sizes, Nanotoxicology. 11(2), 168-183. testing of synergistic/antagonistic, dose level $\square$ dependent, or dose ratio $\square$ dependent effects in mixture dose $\square$ response analysis. Environmental Toxicology and Chemistry. 24, 27012713.

27. Katsumity, A., Gilliland, D., Arostegui, I., Cajaraville M.P., 2015. Mechanisms of Toxicity of Ag Nanoparticles in Comparison to Bulk and Ionic Ag on Mussel Hemocytes and Gill Cells. Plos One. 10(6): e0129039.

28. Krutyakov Y.A., Kudrynskiy A.A., Olenin A.Y., Lisichkin G.V., 2008. Synthesis and properties of silver nanoparticles: advances and prospects. Russ. Chem. Rev. 77, 233 
602

603

604

605

606

607

608

609

610

611

612

613

614

615

616

617

618

619

620

621

622

623

624

625

29. Lahive, E., Matzke, M., Durenkamp, M., Lawlor, A. J., Thacker, S. A., et al., 2017. Sewage sludge treated with metal nanomaterials inhibits earthworm reproduction more strongly than sludge treated with metal metals in bulk/salt forms. Environmental Science: Nano. 4(1), 7888.

30. Luoma, S.N., Ho, Y.B., Bryan G., 1995. Fate, bioavailability and toxicity of silver in estuarine environment. Marine Pollution Bulletin. 31, 44-54

31. Markus, A. A., Parsons, J. R., Roex, E. W. M., De Voogt, P., Laane, R. W. P. M., 2015. Modeling aggregation and sedimentation of nanoparticles in the aquatic environment. Science of the Total Environment. 506, 323-329.

32. Markus, A. A., Parsons, J. R., Roex, E. W. M., De Voogt, P., Laane, R. W. P. M., 2016. Modelling the transport of engineered metallic nanoparticles in the river Rhine. Water research. 91, 214-224.

33. Moore M.N., 2006. Do nanoparticles present ecotoxicological risks for the health of the aquatic environment? Environmental international. 32, 967-976

34. Parsai, T., Kumar, A., 2021. Weight-of-evidence process for assessing human health risk of mixture of metal oxide nanoparticles and corresponding ions in aquatic matrices. Chemosphere. 263, 128289.

35. PROSPEcT. Protocol for nanoparticle dispersion. 2010.

36. Qin, X.X., Waite, J.H., 1998. A potential mediator of collagenous block copolymer gradients in mussel byssal threads. Proceedings of the National Academy of Sciences. 95(18), 10517-10522.

37. Santore, R.C., C.T., Driscoll, 1995. The chess model for calculating chemical equilibria in soils and solutions. Chemical Equilibrium and Reaction Models, SSSA Special Publication 42, The Soil Society of America, American Society of Agronomy 
38. Schiavo, S., Duroudier, N., Bilbao, E., Mikolaczyk, M., Schäfer, J., Cajaraville, M. P., Manzo, S., 2017. Effects of PVP/PEI coated and uncoated silver NPs and PVP/PEI coating agent on three species of marine microalgae. Science of the Total Environment. 577, 45-53. edulis. Helg. Meeres., 33, 68-78. Spurgeon, D. J., 2016. Multigenerational exposure to silver ions and silver nanoparticles

41. Sharma V.K., Yngard R.A., Lin Y., 2009. Silver nanoparticles: green synthesis and their antimicrobial activities. Adv. Colloid Sur. Interface 145, 83 of nanometals versus metal ions. Environmental international. 37, 1083-1097 measuring silver nanoparticle concentration and dissolution in seawater by UV-Vis. Science of the total environment. 618, 597-607. Medicinal and ConsumerApplications: A Patent Review of the Past Decade (2007-2017). Antibiotics 7(4): 93

45. Singh, R., Shedbalkar, U.U., Wadhwani, S.A., Chopade, B.A., 2015. Bacteriagenic silver nanoparticles: synthesis, mechanism, and applications. Applied microbiology and biotechnology. 99(11), 4579-4593. zinc and cadmium in the mussel, Mytilus galloprovincialis, determined by autometallography. Tissue and Cell. 28(5), 557-568. 
651 47. Timerbaev, A. R., Kuznetsova, O. V., Keppler, B. K., 2021. Current trends and challenges 652 in analysis and characterization of engineered nanoparticles in seawater. Talanta. 226: $653 \quad 122201$.

654 48. UNI EN ISO 17294-2 (2016) Water quality: Application of inductively coupled plasma 655 mass spectrometry (ICP-MS). Part 2: determination of selected elements including uranium 656 isotopes.UNI - Ente Nazionale Italiano di Unificazione database. pp. 1-31.

657 49. Xu, Z., 2013. Mechanics of metal-catecholate complexes: the roles of coordination state and 658 metal types. Scientific reports. 3(1), 1-7.

659 50. Yu, J., Wei, W., Danner, E., Ashley R.K., Israelachvili, J.N., Waite, H., 2011. Mussel 660 protein adhesion depends on interprotein thiol-mediated redox modulation. Nat Chem Biol. $661 \quad 7,588-590$

662 51. Zhao, H., Robertson, N.B., Jewhurst, S.A., Waite, J.H., 2006. Probing the adhesive 663 footprints of Mytilus californianus byssus. Journal of Biological Chemistry. 281(16), 11090$664 \quad 11096$.

665 